\title{
Structural and functional heterogeneity of hemocyanin: intra- and inter-specific comparison in four species of portunid crabs (Crustacea: Portunidae)
}

\author{
F. Giomi - S. Raicevich - A. Ferrarese • \\ F. Pranovi · P. Di Muro $\cdot$ M. Beltramini
}

Received: 12 May 2006/ Accepted: 25 October 2006/ Published online: 6 January 2007

(C) Springer-Verlag 2007

\begin{abstract}
This work is focused on hemocyanin (Hc) heterogeneity at population level and on the biochemical characterization of the different subunit patterns. Two different approaches have been used: we have characterized Hc subunit composition to describe the subunit polymorphism. Then, we have measured the Hc oxygen-binding affinity to disclose the physiological implications of such heterogeneity. In order to evaluate the intra- and inter-specific variability, different populations of Liocarcinus depurator, Liocarcinus marmoreus, Liocarcinus holsatus, Necora puber (Crustacea: Portunidae), from British Isles and Adriatic Sea, have been sampled. Results indicate that Hc polymorphism normally occurs at both intra- and interspecific levels and involves the protein subunit type.
\end{abstract}

Communicated by R. Cattaneo-Vietti, Genova.

Declaration: All the experiments comply with the current laws of Italy.

F. Giomi · P. Di Muro · M. Beltramini $(\bowtie)$

Department of Biology, University of Padova,

Viale G. Colombo 3, 35131 Padova, Italy

e-mail: beltmar@bio.unipd.it; mariano.beltramini@unipd.it

S. Raicevich

ICRAM, Central Institute for Research Applied to the Sea, Loc. Brondolo, 30015 Chioggia, Venice, Italy
A. Ferrarese
VIMM, Venetian Institute of Molecular Medicine,
Via G. Orus 2, 35129 Padova, Italy
F. Pranovi
Department of Environmental Sciences,
University of Venice, Celestia,
Castello 2737/b, 30122 Venice, Italy

These evidences extend to the portunid Hc the concept of molecular heterogeneity within species that have been previously reported for other decapod and amphipod crustaceans. Besides, the results support the view that subunit composition of crustacean Hcs is almost species-specific, but also that closely related species share a common pattern. Furthermore, this heterogeneity corresponds to different stability of the native oligomers quaternary structure and different oxygen affinity. The results are discussed in relation with the environmental regimes that characterize the different sampling areas. In addition to Hc, the hemolymph collected in specimens from different sampling areas contained also a non-respiratory pseudo-Hc. This paper reports for the first time the occurrence of pseudo-Hc at the level of population.

\section{Introduction}

Crustacean hemocyanins (Hcs) are complex molecules resulting from aggregation of $\sim 75 \mathrm{kDa}$ subunits, arranged in hexameric or multiple hexameric structures. In brachyuran crabs two aggregation states have been described: a prevailing dodecameric fraction together with an hexameric one (Terwilliger 1982; Ellerton et al. 1983; Markl 1986). The ratio between the dodecameric and hexameric fractions is considerably variable among species, populations and also specimens (Mangum et al. 1991). Furthermore, given subunits are recognized as determinant for building the higher aggregation states (Markl and Decker 1992). This wide structural plasticity could provide the basis for physiological adaptation to selective environmental pres- 
sures. These considerations are further supported by two remarkable aspects of crustacean Hcs: the speciesspecificity of subunit composition and the molecular heterogeneity among distinct populations. The whole Hc oligomers are composed by a complex assemblage of a number of distinct monomeric subunits, ranging from 1 to 17 (Terwilliger et al. 1979; Mangum and McKenney 1996). The phenotypic composition of subunits patterns, resolved by native and SDS-PAGelectrophoresis, have been described as species-specific in several decapods (Reese and Mangum 1994; Mangum 1996; Mangum and McKenney 1996; Mangum and Greaves 1996; Schmitt 2002), isopods and amphipods (Terwilliger 1982; Hodgson and Spicer 2001).

Recently, the information about sequence identity of arthropod Hc was used (Terwilliger 1998; Decker and Terwilliger 2000; van Holde et al. 2001; Jaenicke and Decker 2004) to trace the relationships within or between higher taxa (Kusche and Burmester 2001; Ballweber et al. 2002; Burmester 2004) or between proteins of the Hcs superfamily which includes prophenoloxidases, arylphorins, hexamerins, cryptocyanin in addition to arthropod and mollusk Hcs (Burmester 2001, 2002; Immesberger and Burmester 2004).

Numerous studies have been addressed at the intraspecific variability to analyze the correlation among functional and structural properties of $\mathrm{Hc}$ with the ontogenetic and ecological traits of animals (Sullivan et al. 1974; Mangum and Rainer 1988; Callicott and Mangum 1993; Mangum and Greaves 1996; Durstewitz and Terwilliger 1997; Brown and Terwilliger 1998; Terwilliger and Dumler 2001). These studies have considered the molecular heterogeneity of Hc among populations as an essential feature for the adaptive processes suggesting that variations in the native subunit patterns generate complex hetero-hexamers and contribute to distinct oxygen-binding features (cooperativity, oxygen affinity, allosteric regulation, etc.). The subunits heterogeneity among populations is in relation with the sexual, seasonal and ecological variability emphasizing the functional role of Hc polymorphisms (Bellelli et al. 1988; Mangum 1990, 1993, 1994; Mangum and McKenney 1996; Spicer and Baden 2001; Spicer and Hodgson 2003a, b). The oxygentransport capabilities result to be varied by different expression of distinct polypeptide chains that have different oxygen-binding properties (Terwilliger 1998). Such analyses have pointed out the role of the physiological plasticity of this protein in adaptive strategies at the level of both individuals and species.

This work was focused on Hc polymorphisms and functional properties among populations of closely related species. We have analyzed the properties of oligomers isolated from native hemolymph and comparatively estimated intra- and inter-specific differences in the $\mathrm{Hc}$ subunits patterns. Finally, the comparison among population was related to the environmental regimes of the different sampling areas. In this framework, the wide geographical distribution, the catchability to trawl fishing gears, and the considerable amount of molecular and physiological data in literature, make the portunid crabs (Crustacea: Portunidae) well suited for this analysis.

The intra-specific study has been performed by collecting Liocarcinus depurator (Linnaeus, 1758) specimens from the Northern Adriatic Sea and from various locations around the British Isles (Clyde Sea, Irish Sea, English Channel). In the Northern Adriatic Sea, L. depurator is spread in the sublittoral (Šimunović 1999) whereas in the British Isles coasts it exhibits a wider bathymetric distribution, being spread from the lower shore to sublittoral (Ingle 1996). The inter-specific part has been performed considering other species of the genus Liocarcinus such as $L$. holsatus (Fabricius, 1798) and L. marmoreus (Leach, 1814) and Necora puber (Linnaeus, 1767), collected in the same areas around the British Isles. L. marmoreus is distributed from the lower shore to sublittoral (Ingle 1996) in contrast to N. puber and L. holsatus, which are known to occupy even shallower habitats (intertidal and shallow water; rock pools to shallow sublittoral and offshore, respectively) (Ingle 1996).

\section{Materials and methods}

\section{Samples collection and preparation}

Crabs (50-60 inter-molt, adult individuals per sample, with the exception of $N$. puber, 20-25 individuals per sample) were randomly collected in March 2002 in the Adriatic Sea and in August and October 2002 in the British Island Seas (Table 1 and Fig. 1). The sampling sites differed both in terms of depth (from 15 to $75 \mathrm{~m}$ ) and in terms of bottom sediment texture (see Table 1 and Fig. 1).

Sampling activity was always carried out by means of trawl fishing gear, in the English Channel and Irish Sea (Conwy Bay) on board of the R/V Prince Madog by means of a beam-trawl, in the Clyde Sea on board of the $\mathrm{R} / \mathrm{V}$ Aora by means of a otter trawl, and the Northern Adriatic Sea on board of a commercial vessel by means of a "rapido" trawl.

When on board, alive crabs without evident body injures were randomly sorted from the whole catch and brought into tanks containing sea-water. The hemol- 
Table 1 Sampled populations (as species and sample number) and sampling areas features (location, sampling date, station depth, sediment texture)

\begin{tabular}{|c|c|c|c|c|c|}
\hline Species & Sample & Sampling area & Sampling date & Mean depth (m) & Sediment texture \\
\hline L. depurator & $\mathrm{LdA}$ & Northern Adriatic Sea & 15 March 2002 & 27 & Sandy gravel \\
\hline L. depurator & LdEc1 & English Channel & 24 August 2002 & 31 & Mud \\
\hline L. depurator & LdEc2 & English Channel & 25 August 2002 & 43 & Muddy gravel \\
\hline L. depurator & LdEc3 & English Channel & 31 August 2002 & 24 & Muddy gravel \\
\hline L. depurator & LdCs & Clyde Sea & 4 October 2002 & 75 & Mud \\
\hline L. depurator & LdIs & Irish Sea (Conwy Bay) & 8 October 2002 & 15 & Sand \\
\hline L. holsatus & LhEc3 & English Channel & 29-30 August 2002 & 24 & Sandy gravel \\
\hline L. holsatus & LhIs & Irish Sea (Conwy Bay) & 10 October 2002 & 15 & Sand \\
\hline L. marmoreus & $\mathrm{LmEc} 4$ & English Channel & 30 August 2002 & 64 & Sandy gravel \\
\hline N. puber & $\mathrm{NpEc} 3$ & English Channel & 30 August 2002 & 24 & Sandy gravel \\
\hline N. puber & NpIs & Irish Sea (Conwy Bay) & 24 October 2002 & 15 & Sand \\
\hline
\end{tabular}

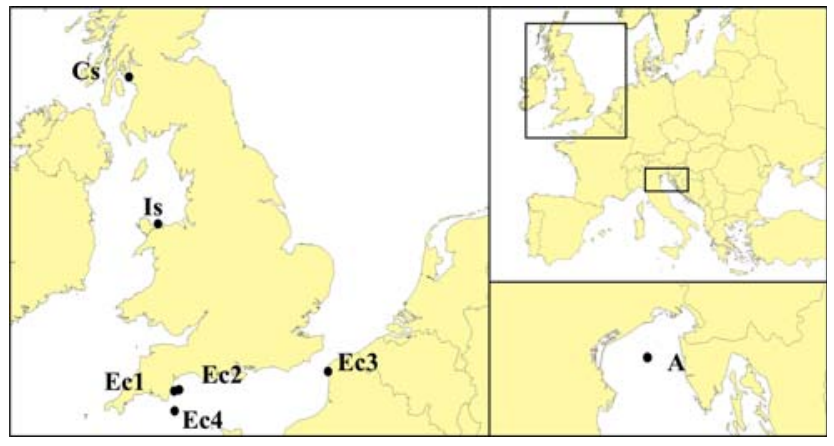

Fig. 1 Location of sampling sites. Ec English Channel, Cs Clyde Sea, Is Irish Sea, $A$ Northern Adriatic Sea. For details see Table 1

ymph was immediately withdrawn by a needle injected into the pericardium. Hemolymph samples were then stored at $-20^{\circ} \mathrm{C}$ after addition of $0.1 \%$ PMSF and $20 \%$ sucrose $(\mathrm{w} / \mathrm{v})$. For analytical purposes, the samples were thawed, dialyzed overnight against Tris $/ \mathrm{HCl}$ $50 \mathrm{mM}, \mathrm{CaCl}_{2} 20 \mathrm{mM}$, PMSF $0.1 \%$, pH 7.5 and subsequently centrifuged at $45,000 \mathrm{~g}$ for $25 \mathrm{~min}$ (Beckman J2-21) to remove cells and other high molecular weight material. Hc was finally purified by centrifugation at 296,000 $g$ for $5 \mathrm{~h}$ (Beckman XL-70) and, after the removal of supernatant, the pellets was resuspended in Tris/ $\mathrm{HCl} 50 \mathrm{mM}, \mathrm{CaCl}_{2} 20 \mathrm{mM}, \mathrm{pH}$ 7.5. The protein concentration and the percentage of oxy-Hc was determined using the absorption coefficient at $278 \mathrm{~nm}$ $\left(1.24 \mathrm{mg}^{-1} \mathrm{ml} \mathrm{cm}^{-1}\right)$ and the absorbance ratio $A_{336} / A_{278}=0.21$ for a preparation containing $100 \%$ oxy-Hc, respectively (Dainese et al. 1998). These species dependent values well apply for portunid crabs.

\section{Dissociation of hemocyanin}

The aggregation state of Hcs depends on the $\mathrm{pH}$ and the presence of bivalent cations $\left(\mathrm{Ca}^{2+}\right.$ or $\left.\mathrm{Mg}^{2+}\right)($ Markl and Decker 1992). In $50 \mathrm{mM}$ Tris/HCl, $\mathrm{pH} 7.5$, and in the presence of $20 \mathrm{mM} \mathrm{CaCl}_{2}$, the protein is found in its native aggregation state. Upon removing $\mathrm{Ca}^{2+}$ ions, by dialysis against $10 \mathrm{mM}$ EDTA, and increasing the $\mathrm{pH}$ to 9.2, dissociation of the protein into monomers occurs. For these preparations the Hc samples were dialyzed at $4^{\circ} \mathrm{C}$, performing three consecutive changes of buffer solution during $24 \mathrm{~h}$.

\section{Chromatographic and electrophoretic analyses}

The different aggregation states and the dissociation behavior of the investigated Hcs were studied in gelfiltration chromatography using a Superose ${ }^{\circledR} 6$ HR 10/ 30 analytical column in a FPLC apparatus (Pharmacia) previously equilibrated with the desired buffer. The flow rate was $0.5 \mathrm{ml} \mathrm{min}{ }^{-1}$ throughout. The elution profiles were recorded on a PC and the area under each peak, relatively to the total amount of eluted protein, was quantified using Origin 7.0. Analytical electrophoresis was carried out in vertical mini-gel slabs using Bio-Rad Mini Protean ${ }^{\circledR} 3$ and runs were carried out at the constant current of $20 \mathrm{~mA}$ per gel. Native PAGE under dissociating conditions, performed as in Markl et al. (1979), was carried out in discontinuous gels consisting of a stacking gel $(4 \% \mathrm{pH}$ 9.6) over a resolving gel (8.5\% $\mathrm{pH}$ 9.6). SDS-PAGE was performed using a discontinuous $\mathrm{pH}$ system detailed in Fling and Gregerson (1986), SDS gels consisting in a stacking gel $(4 \%, \mathrm{pH} 6.8)$ over a resolving gel $(8.5 \%, \mathrm{pH} 8.6)$.

\section{$\mathrm{N}$-terminal sequencing}

The Hc subunits, previously separated by SDS-PAGE, were transferred to a PVDF membrane (Immobilon-P) by tank transfer blotting at $40 \mathrm{~V}$, overnight at $4^{\circ} \mathrm{C}$ using Bio-Rad Trans-Blot cell ${ }^{\circledR}$. The membranes were 
stained in Ponceau Red and subsequently dried in air in order to excise and separate the different subunits.

Amino acid sequences were determined by automated Edman degradation in a pulsed liquid-phase sequencer (Model: Procise HT-491, Applied Biosystems, Foster City, CA, USA) equipped with an on-line HPLC system for PTH-amino acid identification. Protein containing bands, electroblotted on PVDF membrane were excised, washed successively with methanol, water and methanol, and introduced in the sequencer reaction chamber. Up to five pieces of the same membrane bound sample $(5 \mathrm{~mm})$ were loaded into the cartridge to maximize amino acid recovery. All samples were run in the pulsed liquid-phase mode of Edman chemistry, with $n$-heptane/ethyl acetate as the extraction solvent for anilinothiazolinones. For each sample 12 sequencing cycles were performed and amino acid positions assigned by means of peak area(s) and retention time(s). All solvents and reagents were from Applied Biosystems (Foster City, CA, USA).

The sequences obtained were aligned, using ClustalX, with the N-terminal regions of the following Hcs, indicated with the abbreviations used in Table 2 and by the SwissProt and NCBI accession numbers: Pacifastacus leniusculus (Pac.le.), Q8MUH8, AAM81357; Palinurus vulgaris sub 1 (Pal.vu.1), Q95P19, CAC69243; Pontastacus leptodactylus (Pon.le.B), P83180, P83180; Homarus americanus (Hom.am.A), Q9NFR6, CAB75960; Callinectes sapidus (Cal.sa.), Q9NGL5, AAF64305; Penaeus vannamei (Pen.va.), Q26180, CAA57880; Cancer magister (Can.ma.6), U48881, AAA96966. Non-respiratory Hc were also included: C. magister cryptocyanin (Can.ma.cryp), AAD09762, O96992; H. americanus pseudo-Hc 1 (Hom.am.ps-Hc2), CAB38042, Q6KF82; H. americanus pseudo-Hc 2 (Hom.am.ps-Hc2), CAB38043, Q6KF81.

\section{Oxygen-binding measurements}

Oxygen-binding curves have been determined in $50 \mathrm{mM}$ Tris/ $\mathrm{HCl}$, pH 7.5, $20 \mathrm{mM} \mathrm{CaCl} 2$ with the tonometric method as described by Molon et al. (2000) and performed with a Hewlett Packard HP 8452 spectrophotometer at constant temperature of $20^{\circ} \mathrm{C}$, using Hc solutions having an absorbance at $334 \mathrm{~nm}$ of about 0.5 . The $\mathrm{Hc}$ solution $(5 \mathrm{ml})$ was placed into a tonometer $(233.0 \mathrm{ml})$ equipped with a quartz cuvette $(d=1 \mathrm{~cm})$. The absorption spectra of copper-peroxide band $(\lambda=338 \mathrm{~nm})$ were measured at the equilibrium after each addition, with Hamilton gastight syringes, of know volumes of water-saturated oxygen. The relative $p \mathrm{O}_{2}$ was calculated using the following equation: $p \mathrm{O}_{2}=\frac{\left(V_{\mathrm{O}_{2}} \times P_{\text {water }}\right)}{V}$

were $V_{\mathrm{O}_{2}}$ is the volume of oxygen injected, $P_{\text {water }}$ is the atmospheric pressure corrected for the water tension and $V$ is the internal volume of the tonometer.

The Hc relative saturation was calculated using the following equation:

$Y=\frac{A_{x}-A_{0}}{A_{\infty}-A_{0}}$

where $A_{0}, A_{\infty}$ and $A_{x}$ are the values of spectroscopic absorption in absence of oxygen, at complete oxygen saturation and at different $p \mathrm{O}_{2}$, respectively. Each oxygen-binding measurements were performed in triplicate and interpolated with Hill equation.

\section{Results}

Intra-specific comparison

The Hcs isolated from $L$. depurator sampled in the different areas, as well as the Hcs isolated from the other portunid species, exhibit the same oligomeric state under conditions that stabilize the higher aggregation forms. Furthermore, on increasing the $\mathrm{pH}$ and in the absence of divalent cations, all studied Hcs dissociate retaining the oxygen-binding capability. The gel-filtration chromatographic pattern of a $L$. depurator Hc (Fig. 2), sample indicated in Table 1 as LdEc3, confirms, as in other portunid crabs (Dainese et al. 1998) that at $\mathrm{pH}$ around neutrality and with $\mathrm{Ca}^{2+}$ $20 \mathrm{mM}$, the dodecameric aggregate is prevalent (peak A, Fig. 2, upper panel) with a smaller fraction of material eluting as hexameric oligomer (peak B, Fig. 2, upper panel). The dodecameric and hexameric fractions were pooled and analyzed by absorption spectroscopy (spectra shown in Fig. 2, panels a, b). The eluted material of peak A $(74.3 \%$ of LdEc3 total protein) shows the typical band of oxy-Hc at $338 \mathrm{~nm}$ whereas peak B $(25.7 \%)$ is almost completely devoid of such band. These results show that the dodecameric material is originating from oxygen-binding $\mathrm{Hc}$ whereas the less abundant hexameric material contains a non-functional protein, in addition to traces of Hc. Thus, in addition to the oxygen transporting $\mathrm{Hc}$ in the dodecameric form, $L$. depurator express a non-respiratory protein in a hexameric aggregation state.

Under dissociating conditions, crustacean Hcs are almost quantitatively converted into the monomeric forms (Markl and Decker 1992). As expected, this 
Table 2 Multiple alignment of the N-terminal amino acid sequences of crustacean respiratory Hcs (upper panel) and nonrespiratory Hcs (central panel)

\begin{tabular}{ll}
\hline Respiratory Hc & \\
\hline Pac.le. & TVSADTDVAHQQ \\
Pal.vu.1 & SDVHSSDNAHKQ \\
Pon.le. & -DASGATLAKRQ \\
Hom.am.A & NDASGDSTAKRQ \\
Cal.sa & DSPGGASNAQKQ \\
Pen.va. & SDAGGESDAQKQ \\
Can.ma.6 & -TAGGAFDAQKQ \\
HCY1_LIODE & DSPGGASDAQKQ \\
HCY2_LIODE & DAPGGASDAQKQ \\
HCY1_NECPU & DSPAGVSDAQKQ \\
\hline Non-respiratory Hc & \\
\hline Can.ma.cryp & \\
Hom.am.ps-Hc1 & DEPDGVSKYQKQ \\
Hom.am.p. -Hc2 & DEPDGVPTAQKQ \\
PHCY_LIODE & DEPDGVPTAQKQ \\
PHCY_LIOHO & DEPDGVPTHQKQ \\
PHCY_LIOMA & DEPDGVPTHQKQ \\
PHCY_NECPU & DEPDGVPTRQKQ \\
\hline
\end{tabular}

Identical amino acids

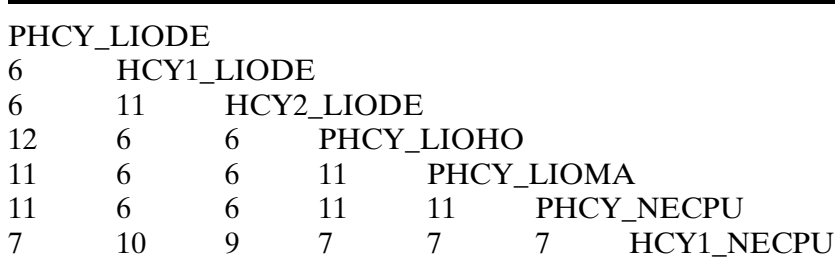

The sequences of $L$. depurator, L. holsatus, L. marmoreus and $N$. puber are indicated in capital letters. In lower panel, the number of identical amino acid positions in pairwise comparison of $\mathrm{N}$ terminal sequences, from this study, are specified

occurs also with $L$. depurator Hc as shown by gel-filtration where the prominent protein peak correspond to monomeric Hc (Fig. 3). The quantification of the chromatographic patterns shows that the protein sample collected from L. depurator in the Northern Adriatic sea (Fig. 3, insert, column LdA) is almost quantitatively converted into the monomeric component, whereas the sample corresponding to LdEc3 results to be more resistant to the dissociation (Fig. 3, dashed line, insert, column LdEc3) with a significant fraction of protein which still remains in the aggregated form after $24 \mathrm{~h}$. Other populations such as LdIs exhibit an intermediate stability while population LdCs behaves essentially as LdA.

In order to better specify the different intrinsic stabilities of the oligomers under dissociating conditions (Markl and Decker 1992), we focused on LdA and LdEc3 Hcs testing the $\mathrm{pH}$ dependence of dissociation. To avoid interferences due to the stabilizing effects of
$\mathrm{Ca}^{2+}$ ions, EDTA was included in the incubation medium at the various $\mathrm{pH}$. The results are summarized in Fig. 4 where each panel reports the $\mathrm{pH}$ dependence of the percent abundance of the different aggregation forms, as it results from the quantification of the gelfiltration patterns each carried out at the indicated $\mathrm{pH}$ values. It is worth noting that the removal of $\mathrm{Ca}^{2+}$ does not induce per se dissociation of the dodecamers, as long as the $\mathrm{pH}$ is maintained around neutrality. The Hc isolated from population $\mathrm{LdEc} 3$ results to be more stable than LdA, in agreement with the results of Fig. 3, and the curves relative to each component demonstrate that the dissociation process follows the dodecamer-hexamer-monomer order. The $\mathrm{pH}$ effect is shifted by about 0.5 units between LdA and LdEc3. These results demonstrate that sample LdEc3 is characterized not only by the presence of a more abundant hexameric fraction but also that the Hc, both the dodecameric and the hexameric oligomers, are more stable to dissociation.

The results of PAGE, under alkaline conditions (Fig. 5) confirm this observation. A three-bands pattern results from dissociation of the protein pool; however the persistence of aggregated material in populations LdEc3 and LdIs is evident from the slow migrating band. This band is stronger in LdEc3, smaller yet appreciable in LdIs and absent in LdEc1, LdEc2, LdCs, whereas in the case of LdA the hexamers dissociate during the run, causing the observed the smear.

A further approach to characterize the $L$. depurator hemolymph protein pattern consisted in performing SDS-PAGE on the total material isolated by ultracentrifugation. The results in Fig. 6 show, in all samples studied, a two- to three-bands pattern (Lioc.dep 1, 2,3 ) with molecular weight around $75 \mathrm{kDa}$ (calibration not shown). Population LdEc3 exhibits an almost equal amount of each band, LdIs and LdA show a lower amount of band 1 while the presence of band 1 is almost negligible in LdEc1, LdEc2, LdCs samples.

Taken together these results of gel-filtration (Fig. 3), PAGE (Fig. 5) and SDS-PAGE (Fig. 6) indicate that all populations where band 1 is found are characterized also by an $\mathrm{Hc}$ that is more stable to dissociation. This finding is in line with the concept of intra-specific heterogeneity in $L$. depurator hemolymph proteins.

To characterize the different subunits corresponding to band 1, 2 and 3, the SDS-PAGE bands of LdEc3 were transfer-blotted on a PVDF membrane and submitted to Edman degradation to perform the N-terminal sequencing. The sequences obtained (SwissProt accession numbers: band $1=$ PHCY_LIODE, P84460; band 2= HCY1_LIODE, P84461 band $3=$ HCY2_LIODE, P84462) were aligned, using ClustalX, 
Fig. 2 Gel-filtration chromatography of $L$. depurator Hc, sample described as LdEc3 from Table 1 , in $50 \mathrm{mM}$ Tris $/ \mathrm{HCl}$ buffer at $\mathrm{pH} 7.5$ containing $20 \mathrm{mM} \mathrm{CaCl}_{2}$, Superose $6 \mathrm{HR}$ $10 / 30$ column. Panels a and b report the absorption spectra exhibited by the pooled peaks as indicated by the marks in the elution profile
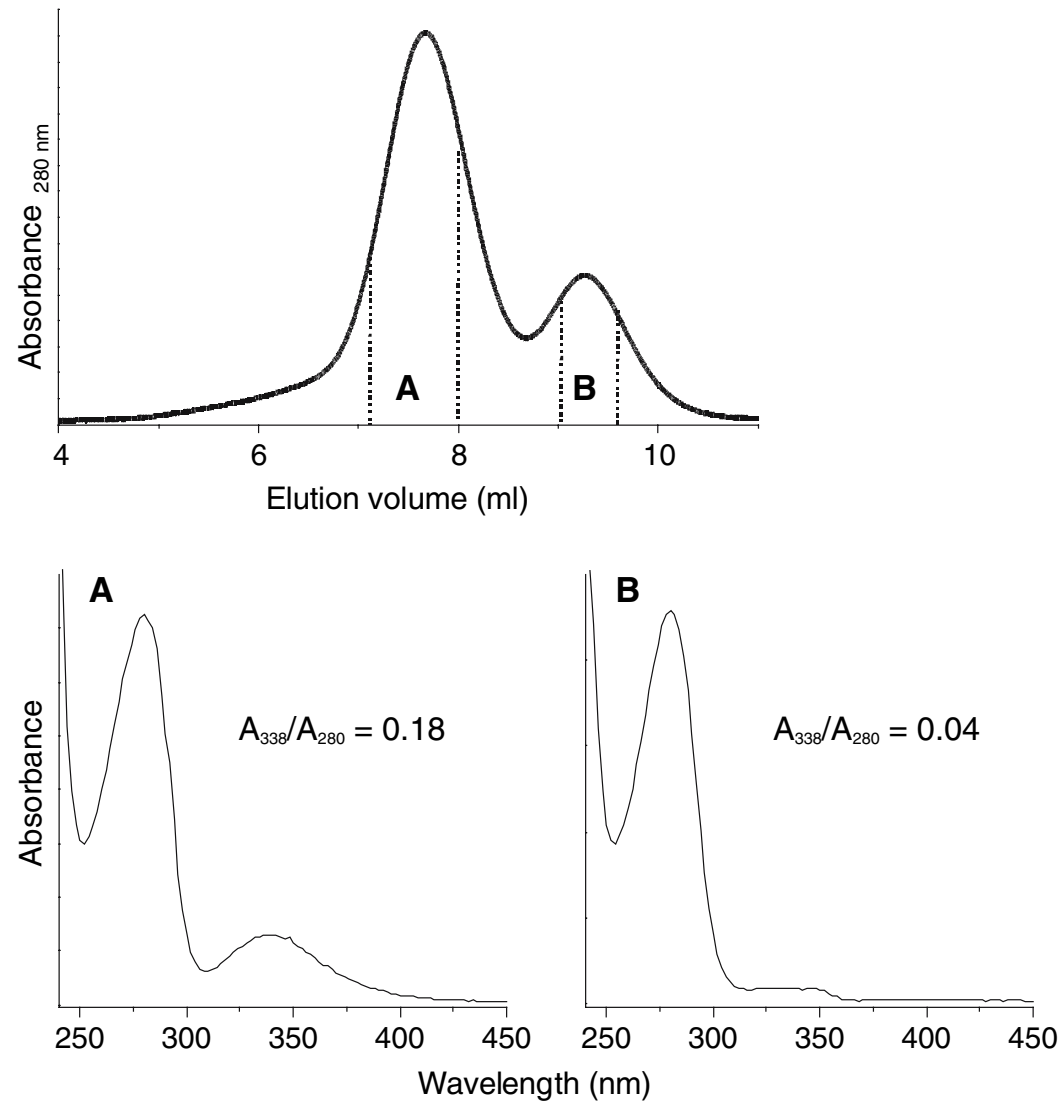

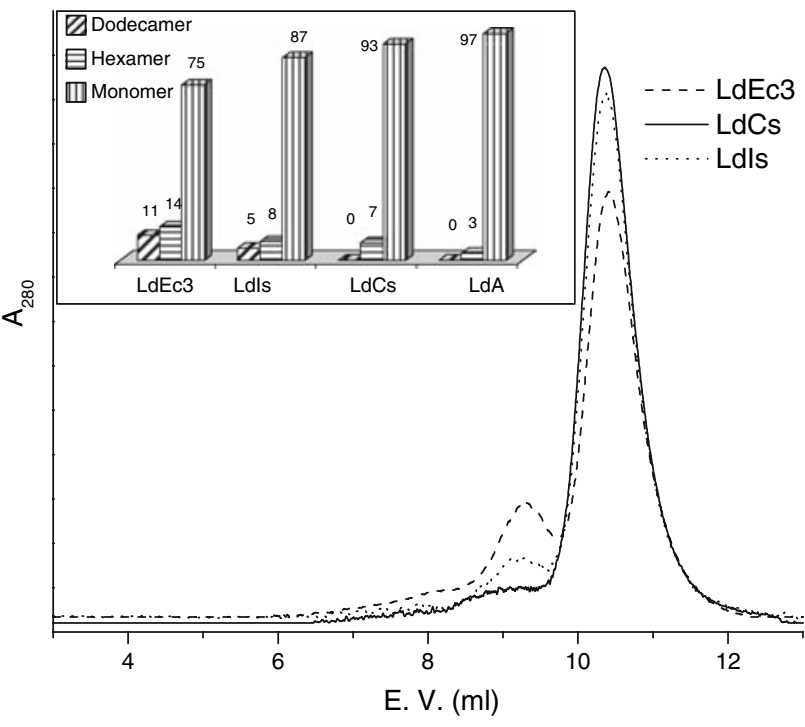

Fig. 3 Gel-filtration chromatography of L. depurator Hc samples described as LdEc1 (solid line), LdEc3 (dashed line) and LdIs (dotted line) from Table 1 . Elution buffer $50 \mathrm{mM}$ Tris/ $\mathrm{HCl}$ buffer at pH 9.2 containing $20 \mathrm{mM}$ EDTA, column Superose 6 HR 10/30 column. Insert: percent values of each oligomeric or monomeric component as deduced by integration of the chromatographic profile, the results include also sample LdA whose profile has not been included with respiratory and non-respiratory $\mathrm{Hc}$ and the results are summarized in Table 2. In the case of band 1, out of 12 residues sequenced, 11 positions are identical with the $\mathrm{N}$-terminal sequence of $\mathrm{PHc}$ from $\mathrm{H}$. americanus (Burmester 1999) and 9 with the cryptocyanin from C. magister (Terwilliger et al. 1999) whereas only 1-5 residues are identical with sequences from crustacean Hcs. Conversely the N-terminal sequences deduced from bands 2 and 3 share up to 11 identical positions with decapod Hcs. These results allow to assign band 1 as PHc and bands 2 and 3 as two different Hc subunits.

The oxygen-binding properties of the Hcs from the different populations have also been studied. For this analysis we have performed in vitro measurements using the same buffer in order to normalize the experimental conditions of the various samples. The oxygen-binding curves of populations LdA, LdEc1, LdEc3, LdCs and LdIs are shown in Fig. 7 where the resulting p50 values also given. These samples have been selected because they allow a comparison between the North Sea and the Adriatic Sea populations as well as between populations exhibiting ( $\mathrm{LdEc} 3$ and LdIs) or not (LdEc1 and LdCs) PHc. It is to be re- 

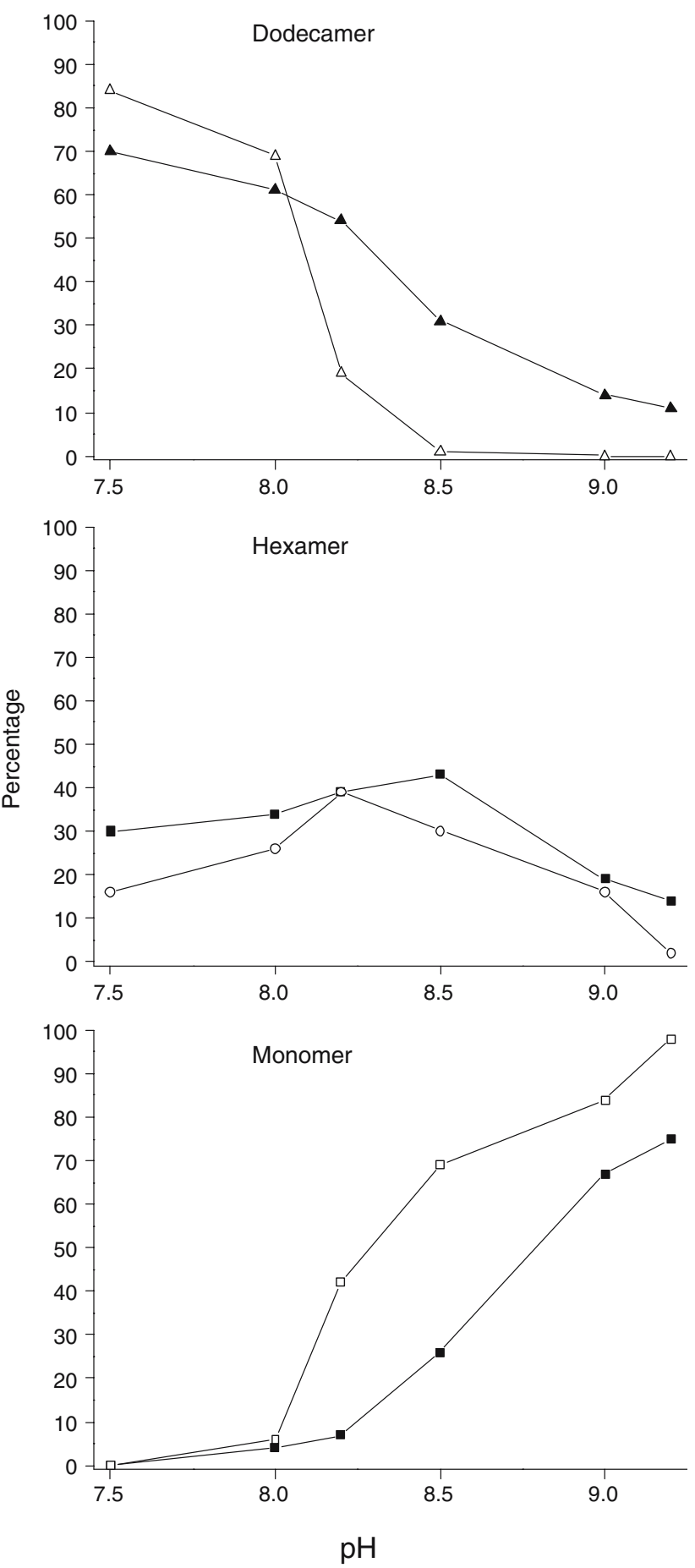

Fig. $4 \mathrm{pH}$-dependence of Hc dissociation process in L. depurator populations LdA (closed symbols) and LdEc3 (open symbols). The $\mathrm{Hc}$ were incubated $50 \mathrm{mM}$ Tris/ $\mathrm{HCl}$ buffer at the indicated $\mathrm{pH}$ values in the presence of $20 \mathrm{mM}$ EDTA. Percentages of the different aggregation states at the indicated $\mathrm{pH}$ values were determined by integration of the peak areas in the gel-filtration elution profiles

marked the significantly lower oxygen affinity of LdA Hc compared with those of the four populations of the North Sea. These results are evidences for a rather high functional heterogeneity of the protein within the different populations. Furthermore, populations of more closely related geographical areas (LdEc3 and LdEc1) are more similar as compared with distantly located populations (LdA vs $\mathrm{LdEc} 3$ or LdEc1).

Inter-specific comparison

Liocarcinus marmoreus, L. holsatus and N. puber Hcs have been collected in the English Channel and Irish Sea, as summarized in Table 1, and comparatively analyzed with native and SDS-PAGEs. The oligomers isolated from the hemolymph collected from the populations of L. holsatus and $N$. puber sampled in the English Channel exhibit higher stability as compared with the populations of the same species sampled in Irish Sea (Fig. 8, panel a, populations Ec3 vs Is). This is demonstrated by the persistence of the slow migrating band under the alkaline $\mathrm{pH}$ conditions of PAGE (9.6). Again, as described above with the L. depurator populations, the peculiar behavior of Ec3 Hc populations can be related with the higher content of the slow migrating component in SDS-PAGE (Fig. 8, panel b).

The qualitative analysis of the SDS electrophoretic patterns also emphasize that the different species can be distinctly distinguished on the basis of their electrophoretic patterns (Fig. 8, panel b) with the presence of 5, 5 and 6 bands in the case of L. holsatus, L. marmoreus and $N$. puber, respectively, as compared with the three-bands pattern of L. depurator Hc.

To identify the slow migrating subunits, the bands, one from $L$. holsatus and L. marmoreus samples and two from $N$. puber, were excided from the PVDF membranes and analyzed for N-terminal sequencing. The results, as shown in Table 2, allow to attribute to PHc three of these subunits and to Hc the fourth one (Table 2, SwissProt accession numbers: L. holsatus $=$ PHCY_LIOHO, P84768; L. marmoreus $=$ PHCY_LIOMA, P84769; N. puber PHCY_NECPU, P84847; HCY_NECPU, P84846). Thus, the heterogeneous expression among populations of this nonrespiratory protein is confirmed also at inter-specific level.

\section{Discussion}

In this work we have to carried out an inter- and intraspecific comparison of Hcs from portunid crabs, sampled in different sites. The first level of comparison add further information to the finding that $\mathrm{Hc}$ subunit compositions are different among species. This aspect have been widely investigated by the works of Mangum in decapod and Spicer in non-decapod crustaceans 
Fig. 5 Native PAGE at $\mathrm{pH}$ $9.6(8.5 \% \mathrm{gel})$ of Hcs sampled from different populations of L. depurator as indicated in

Table 1, the two lanes for each sample include either $5 \mu \mathrm{g} \mathrm{Hc}$ (left lane) or $10 \mu \mathrm{g}$ Hc (right lane). The hexameric and the monomeric fractions are indicated
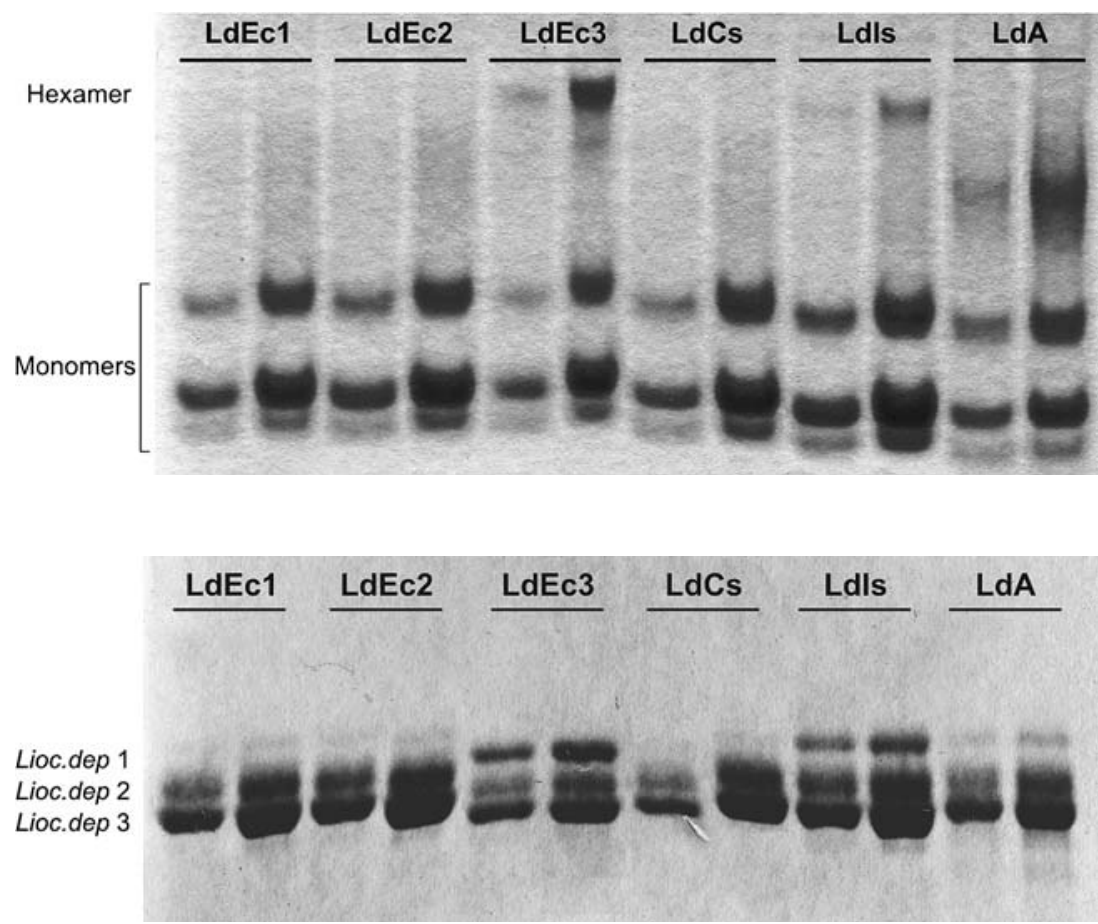

Fig. 6 SDS-PAGE ( $8.5 \%$ of polyacrylamide gel) of Hcs sampled from different populations of $L$. depurator as indicated in Table 1. Either $2 \mu \mathrm{g} \mathrm{Hc}$ (left lane) or $4 \mu \mathrm{g} \mathrm{Hc}$ (right lane) were used. The different bands are identified as $1,2,3$ found that the two closely related species $L$. holsatus and L. marmoreus share a common subunit pattern. These findings agree with the phylogenetic analysis based on molecular and chariotypical data proposed by several authors (Froglia and Manning 2006; Mantovani et al. 1992; Trentini et al. 1989, 1992) and support a closer relationship of L. holsatus and L. marmoreus with $L$. depurator and $N$. puber. In addition the results of this work point out that also the non-respiratory hemolymph protein, pseudo-Hc, is a common feature of the portunid family but its expression does not depend on the taxonomical position of the organisms; rather it seems to be related to environmental stimuli.

The intra-specific level of comparison allows to disclose differences on the $\mathrm{Hc}$ subunit expression within the same species as a function of the sampling areas. Our results further support the current view of a possible influence of the environmental characteristics on the phenotypical expression of Hcs, as discussed in literature. There are indeed several evidences (Bellelli et al. 1988; Mangum and Rainer 1988; Mangum et al. 1991; Mangum 1994) that environmental oxygenation, salinity and temperature may affect the Hc subunit patterns at the level of individuals. These evidences are based both on manipulation of abiotic factors in laboratory experiments (Decker and Föll 2000; Spicer and Hodgson 2003b) and on analytical observation in the field (Rainer et al. 1985; Mangum et al. 1991; Mangum 1994; Spicer and Baden 2001; Spicer and Hodgson 2003a). From our intra-specific analyses on $L$. depu- 
Fig. 8 Electrophoretic analyses of Hcs sampled from different populations of portunid species. Samples are as indicated in Table $1-L$. holsatus (LhEc3, LhIs), $L$. marmoreus (LmEc4), $N$. puber (NpEc3, NpIs). Upper panel: native PAGE ( $\mathrm{pH} 9.6$, $8.5 \%$ PAGE). Lower panel: SDS-PAGE $(8.5 \%$ of polyacrylamide gel). The lanes for the same sample include from left to right either 2, 4 or $6 \mu \mathrm{g} \mathrm{Hc}$

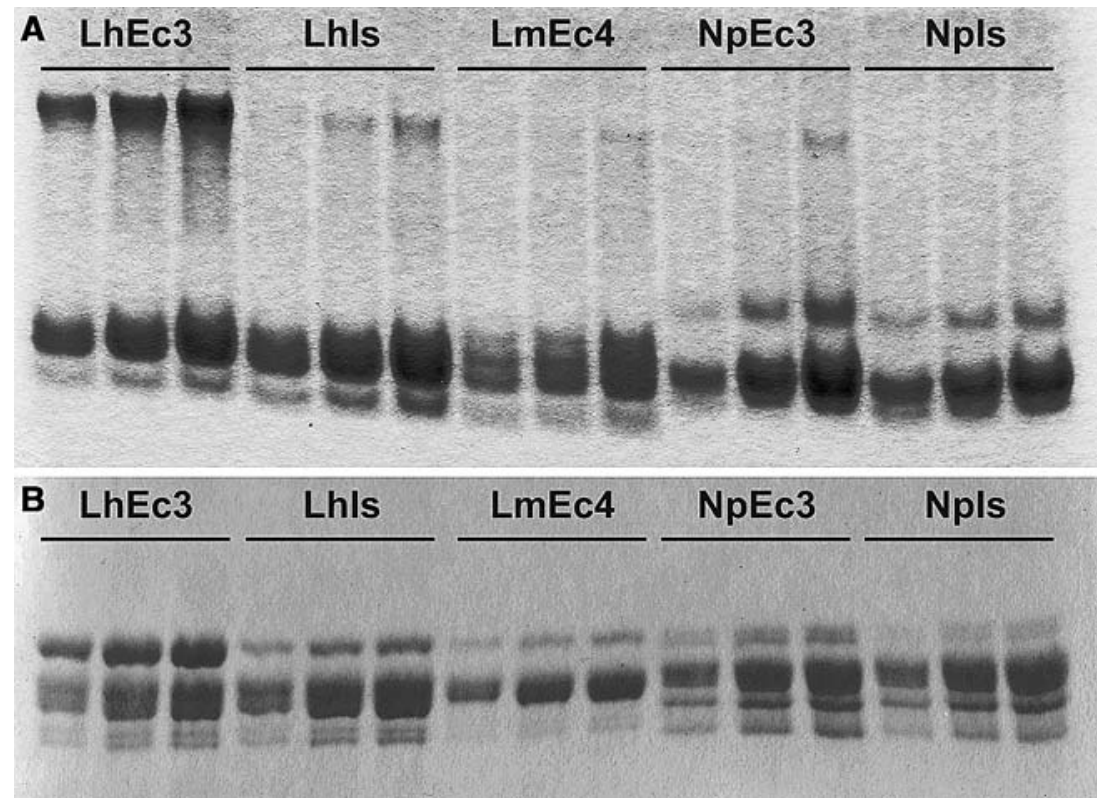

rator Hc, a separation between the Adriatic and the Atlantic populations appears evident as far as the oxygen-binding affinities and the sensitivity to dissociating conditions are concerned. These conclusions agree with the differentiations described by Passamonti et al. (1996/1997) who verified that the Adriatic $L$. depurator appears to be genetically separated and isolated from the gene flow existing between the other Mediterranean and the Atlantic populations.

Neighboring sampling areas, such as Ec1-4, cannot be considered geographically isolated, on consideration that crabs present a larval pelagic phase, that allows a widespread diffusion of individuals. As a consequence, the subunits patterns are not always representative of genetically separated populations but they report the phenotypical/physiological responses to local environmental conditions. Beside, considering the wide timecourse of sampling (Table 1) and the comparable results among various sampling areas and periods, it is reasonable to exclude a seasonal effect on the disclosed differences.

The results achieved with the intra- and inter-specific comparisons highlighted that the capability to modulate the subunit expression is observable in entire local portunid assemblages. This finding suggests that the flexible regulation of molecular composition represents a remarkable potential for simultaneous functional adjustments for the adaptation of animals to local environmental conditions.

From the comparative screening of Hc composition among separated populations of $L$. depurator, the most unforeseen result was to find significantly different amounts of expressed $\mathrm{PHc}$ in addition to the constitutive components of Hc. These findings allow to extend also at population level the occurrence of this non-functional protein, previously demonstrated at the level of individuals of $H$. americanus (Burmester 1999). The identification of this protein as $\mathrm{PHc}$, based on N-terminal sequences of purified electrophoretic bands, provides its first discovery in Brachyuran species as well as at population level. Interestingly, the same $L$. depurator populations exhibiting $\mathrm{PHc}$ have also an $\mathrm{Hc}$ that is more resistant to dissociation under stripping condition, like populations LdEc3 and LdIs (Figs. 5, 6). The above-mentioned correspondence of $\mathrm{Hc}$ oligomer stability and $\mathrm{PHc}$ expression is verified also at inter-specific level. These evidences suggest that environmental stimuli have a dual effect in modulating the phenotypical expression of the two hemolymph proteins. In detail the evidence that, as a general trend exhibited by all analyzed samples, there are distinct differences in the amount of PHc and structural stability as a function not only of the species but, more prominently, of the sampling areas, strongly support the hypothesis the Hc modulation could represent an adaptive response to environmental regimes.

In conclusion, this study further add evidences that environmental forces may play an important role in conditioning the expression of different $\mathrm{Hc}$ subunits thus regulating the structural composition and the functional properties of the whole oligomer. Different subunit patterns result in distinct oxygen-transport properties of the whole oligomer. The capabilities to modulate this expression can strongly contribute to the adaptive plasticity of organisms. 
Acknowledgments The authors wish to thank Prof T. Burmester (University of Hamburg) for his suggestions and criticism, Dr O. Marin (University of Padova) for the availability of sequencing facilities. Prof M.J. Kaiser (School of Ocean Sciences, University of Wales, head of the CREAM group) and Dr R. Ormond (University Marine Biological Station of Millport) for providing all the facilities for sampling and Dr M. Bergmann and Dr J. Hall-Spencer for their collaboration in arranging field work. Furthermore, the scientific staff of the CREAM group (Coastal Research Ecology And Management Group), the crews of R/V Prince Madog and Aora and T. Andersen, A. Candeias, E. Chatzinikolaou, C. Saurel, P. Leontarakis, F. Van Gent, fully collaborated during sampling.

\section{References}

Ballweber P, Markl J, Burmester T (2002) Complete hemocyanin subunit sequences of the hunting spider Cupiennius salei: recent hemocyanin remodeling in entelegyne spiders. J Biol Chem 277:14451-14457

Bellelli A, Giardina G, Corda M, Pellegrini MG, Cau A, Condò SG, Brunori M (1988) Sexual and seasonal variability of lobster hemocyanin. Comp Biochem Physiol A 91:445-449

Brown AC, Terwilliger NB (1998) Ontogeny of hemocyanin function in the dungeness crab Cancer magister: hemolymph modulation of hemocyanin oxygen-binding. J Exp Biol 201:819-826

Burmester T (1999) Identification, molecular cloning and phylogenetic analysis of a non-respiratory pseudo-hemocyanin of Homarus americanus. J Biol Chem 274:13217-13222

Burmester T (2001) Molecular evolution of the arthropod hemocyanin superfamily. Mol Biol Evol 18:184-195

Burmester T (2002) Origin and evolution of arthropod hemocyanins and related proteins. J Comp Physiol B 172:95-107

Burmester T (2004) Evolutionary history and diversity of arthropod hemocyanins. Micron 35:121-122

Callicott KA, Mangum CP (1993) Phenotypic variation and lability of the subunit composition of the hemocyanin of $U c a$ pugilator. J Exp Mar Biol Ecol 165:143-159

Dainese E, Di Muro P, Beltramini M, Salvato B, Decker H (1998) Subunits composition and allosteric control in Carcinus aestuarii hemocyanin. Eur J Biochem 256:350-358

Decker H, Föll R (2000) Temperature adaptation influences the aggregation state of hemocyanin from Astacus leptodactylus. Comp Biochem Physiol A 127:147-154

Decker H, Terwilliger NB (2000) Cops and robbers: putative evolution of copper oxygen-binding proteins. J Exp Biol 203:1777-1782

Durstewitz G, Terwilliger NB (1997) Developmental changes in hemocyanin expression in the Dungeness crab, Cancer magister. J Biol Chem 272:4347-4350

Ellerton HD, Ellerton NF, Robinson HA (1983) Hemocyanin-a current perspective. Prog Biophys Mol Biol 41:143-248

Fling SP, Gregerson DS (1986) Peptide and protein molecular weight determination by electrophoresis using a highmolarity Tris buffer system without urea. Anal Biochem 155:83-88

Froglia C, Manning RB (2006) Marine decapod and Stomatopod Crustacea from Sicily and surrounding seas. Quad Ist Ric Pesca Marittima, Ancona (in press)

Hodgson E, Spicer JI (2001) Subunit compositions of crustacean haemocyanins are species-specific: evidence from non-decapod species. Comp Biochem Physiol 128A:873-888 van Holde KE, Miller KI, Decker H (2001) Hemocyanins and invertebrate evolution. J Biol Chem 276:15563-15566

Immesberger I, Burmester T (2004) Phenoloxidase-like proteins of the tunicate Ciona intestinalis and the origin of the arthropod hemocyanin superfamily. J Comp Physiol B 174:169-180

Ingle RW (1996) Shallow-water crabs. In: Barnes RSK, Crothers $\mathrm{JH}$ (eds) Synopses of the British fauna (new series). Linnean Society, London, p 243

Jaenicke E, Decker H (2004) Functional changes in the family of type 3 copper proteins during evolution. Chembiochem 5:163-169

Kusche K, Burmester T (2001) Diplopod hemocyanin sequence and the phylogenetic position of the Myriapoda. Mol Biol Evol 18:1566-1573

Mangum CP (1990) Inducible $\mathrm{O}_{2}$ carriers in the crustaceans. In: Truchot JP, Lalou B (eds) Animal nutrition and transport processes. 2. Transport, respiration and excretion: comparative and environmental aspects. Karger, Basel, Switzerland, pp $92-103$

Mangum CP (1993) Structural and functional polymorphism of the haemocyanin $\mathrm{O}_{2}$ transport system of the sand fiddler crab Uca pugilator. J Exp Mar Biol Ecol 165:133-141

Mangum CP (1994) Subunit composition of hemocyanin of Callinectes sapidus: phenotypes from naturally hypoxic waters and isolated oligomers. Comp Biochem Physiol B 108:537-541

Mangum CP (1996) Subunit composition of polymorphic hemocyanin in the decapod crustaceans: differences between sibling species. Physiol Zool 69:568-585

Mangum CP, Greaves J (1996) Hemocyanins of the genus Uca: structural polymorphisms and native oligomers. J Exp Mar Biol Ecol 199:1-15

Mangum CP, McKenney AL (1996) Subunit composition of the crustacean hemocyanins: divergence in incipient speciation. Biol Bull 191:33-41

Mangum CP, Rainer JS (1988) The relationship between subunit composition and oxygen binding of blue crab hemocyanin. Biol Bull 174:77-82

Mangum CP, Greaves J, Rainer JS (1991) Oligomer composition and oxygen binding of the blue crab Callinectes sapidus. Biol Bull 181:453-458

Mantovani M, Scali V, Froglia C (1992) Allozymic characterization and phyletic relationships among four species of the genus Liocarcinus STIPSON 1871 (Crustacea Decapoda). Zool Anz 229:237-247

Markl J (1986) Evolution and function of structurally diverse subunits in the respiratory protein hemocyanin from artropods. Biol Bull 171:90-115

Markl J, Decker H (1992) Molecular structure of the arthropod hemocyanins. In: Mangum CP (ed) Blood and tissue oxygen carriers, Adv Comp Environ Physiol 13. Springer, Berlin Heidelberg New York, pp 325-376

Markl J, Hofer A, Bauer G, Markl A, Kempter B, Brenzinger M, Linzen B (1979) Subunit heterogeneity in arthropod hemocyanin: II. Crustacea. J Comp Physiol 133:167-175

Molon A, Di Muro P, Bubacco L, Vasilyev V, Salvato B, Beltramini M, Conze W, Hellmann N, Decker H (2000) Molecular heterogeneity of the hemocyanin isolated from the king crab Paralithodes camtschaticae. Eur J Biochem 267:7046-7057

Passamonti M, Mantovani M, Scali V, Froglia C (1996/1997) Genetic differentiation of European species of Liocarcinus (Crustacea: Portunidae): a gene-enzyme study. Zool Anz 235:157-164 
Rainer J, Mangum CP, Godette G (1985) Subunit heterogeneity of the blue crab (Callinectes sapidus) hemocyanin along a salinity gradient. Am Zool 25:47A

Reese JE, Mangum CP (1994) Subunit composition and $\mathrm{O}_{2}$ binding of the crustacean hemocyanins: interspecific relationships. Biol Bull 187:385-397

Schmitt J (2002) The influence of vertical zonation: differences in hemocyanin structure and function between two crab congeners. M.S. thesis, University of Oregon

Šimunović A (1999) Quantitative and qualitative investigations of the benthic communities in the areas of mobile bottoms of the Adriatic Sea. Acta Adriatica 38:77-197

Spicer JI, Baden SP (2001) Environmental hypoxia and haemocyanin between-individual variability in Norway lobsters Nephrops norvegicus (L.). Mar Biol 139:727-734

Spicer JI, Hodgson E (2003a) Between-population variation in haemocyanin subunit composition of the beachflea Orchestia gammarellus (Crustacea: Amphipoda). J Mar Biol Assoc UK 83:945-947

Spicer JI, Hodgson E (2003b) Structural basis for salinityinduced alteration in oxygen binding by haemocyanin from the estuarine amphipod Chaetogammarus marinus (L.). Physiol Biochem Zool 76:843-849

Sullivan B, Bonaventura J, Bonaventura C (1974) Functional differences in the multiple hemocyanins of the horseshoe crab, Limulus polyphemus L. Proc Natl Acad Sci USA 71:2558-2562
Terwilliger NB (1982) Effect of subunit composition on the quaternary structure of isopod (Ligia pallasii) hemocyanin. Biochemistry 21:2579-2586

Terwilliger NB (1998) Functional adaptations of oxygen-transport proteins. J Exp Biol 201:1085-1098

Terwilliger NB, Dumler K (2001) Ontogeny of decapod crustacean hemocyanin: effects of temperature and nutrition. J Exp Biol 204:1013-1020

Terwilliger NB, Terwilliger RC, Applestein M, Bonaventura C, Bonaventura J (1979) Subunit structure and oxygen binding by hemocyanin of the isopod Ligia exotica. Biochemistry 18:102-108

Terwilliger NB, Dangott L, Ryan M (1999) Cryptocyanin, a crustacean molting protein: evolutionary link with arthropod hemocyanins and insect hexamerins. Proc Natl Acad Sci USA 96:2013-2018

Trentini M, Corni MG, Froglia C (1989) The Chromosomes of Liocarcinus vernalis (Risso, 1916) and Liocarcinus depurator (L., 1758) (Decapoda, Brachiura, Portunidae). Biol Zent Bl 108:163-166

Trentini M, Corni MG, Froglia C (1992) The chromosomes of Carcinus mediterraneus Czerniavsky, 1884, Liocarcinus maculatus (Risso, 1827) and Necora puber (L., 1767) (Decapoda, Brachyura, Portunidae). Zool Anz 228:39-44 